\title{
Control of Glyphosate-Resistant Giant Ragweed (Ambrosia trifida L.) with Isoxaflutole and Metribuzin Tankmix
}

\author{
Scott Ditschun ${ }^{1}$, Nader Soltani ${ }^{2}$, Darren E. Robinson ${ }^{2}$, François J. Tardif ${ }^{1}$, Allan C. Kaastra ${ }^{3}$, \\ Peter H. Sikkema ${ }^{2}$ \\ ${ }^{1}$ Department of Plant Agriculture, University of Guelph, Guelph, Canada \\ ${ }^{2}$ University of Guelph Ridgetown Campus, Ridgetown, Canada \\ ${ }^{3}$ Bayer Crop Science Canada, Guelph, Canada \\ Email: soltanin@uoguelph.ca
}

Received 19 February 2016; accepted 24 April 2016; published 27 April 2016

Copyright (C) 2016 by authors and Scientific Research Publishing Inc.

This work is licensed under the Creative Commons Attribution International License (CC BY).

http://creativecommons.org/licenses/by/4.0/

(c) (7) Open Access

\section{Abstract}

Five field trials were conducted over a two-year period $(2013,2014)$ to determine the control of glyphosate-resistant (GR) giant ragweed with isoxaflutole (IFT) and metribuzin (MTZ) applied alone and in combination. Treatments were designed to assess the dose response of an IFT plus MTZ tank-mix as well as each chemical applied alone to classify the response using Flint's adaptation of Colby's equation. Two factor factorial experiments were performed in the growth room to ascertain the response of IFT versus glyphosate, IFT versus MTZ, and IFT plus MTZ versus glyphosate on single plants. Field experiments evaluated the control of GR giant ragweed with IFT plus MTZ in tank-mix in a 1:4 ratio. The rate of IFT plus MTZ for $80 \%$ control of GR giant ragweed at 4 and 8 weeks after application (WAA) was 518 (104 $\mathrm{g}$ a.i. ha-1 IFT $+414 \mathrm{~g}$ a.i. $\mathrm{ha}^{-1}$ MTZ) and 631

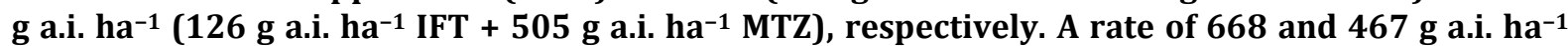
was required to reduce GR giant ragweed density and biomass by $80 \%$, respectively. Field experiments evaluating the control of GR giant ragweed with tank-mixes of IFT plus MTZ, where glyphosate was a constant tank-mix partner, were mostly synergistic. However, the low tank-mix rate $\left(52.5+210 \mathrm{~g}^{\text {a.i. }} \mathrm{ha}^{-1}\right)$ had an additive response for GR giant ragweed biomass reduction. When tested in the greenhouse and growth room, glyphosate susceptible (GS) giant ragweed showed some antagonism with glyphosate and isoxaflutole tank-mixes at rates less than commercial field rates. GR giant ragweed showed an additive response across all treatments in the growth room. Greenhouse experiments evaluating IFT versus MTZ and IFT plus MTZ versus glyphosate revealed all tank-mix treatments to be synergistic at 2 WAA.

\section{Keywords}

Additive, Antagonistic, Giant Ragweed, Glyphosate, Herbicide Resistance, Soybean, Synergistic, 


\section{Introduction}

Giant ragweed (Ambrosia trifida L.) is an annual plant that is a member of the Astereacea family [1]. Its biological attributes make it a very troublesome weed in many cropping systems mostly because of its rapid growth and high competitiveness. For example, the presence of only two giant ragweed plants in an area of 10 square meters decreases corn yield by up to $13 \%$ [2]. Four weeks of giant ragweed competition can cause a yield reduction in soybean up to $25 \%$ [3]. The emergence pattern of giant ragweed can extend from March to late July [2], which means early emerged plants will be more competitive while late emerging individuals will make it difficult to properly time a herbicide application. Since giant ragweed is adapted to no-till conditions, its prevalence has increased with the adoption of this practice especially in soybean [4]. As a result, giant ragweed needs to be managed in crops in order to maintain yields.

While many methods exist for controlling giant ragweed, herbicides are the tools of choice for most growers. Giant ragweed can be effectively controlled with application of 2,4-D and cloransulam [5]. In addition, the introduction of glyphosate-resistant crops has allowed glyphosate to be sprayed POST to control giant ragweed. However, as with any other herbicides, intensive use of glyphosate has resulted in selection of resistance in weeds including giant ragweed [6].

Glyphosate-resistant (GR) giant ragweed was confirmed in Ontario, Canada in 2008 [6]-[8]. Subsequent surveys have confirmed GR giant ragweed in 82 sites across seven counties in Ontario [6] [9]. Multiple resistance to glyphosate and acetolactate synthase (ALS) inhibiting herbicides has also been confirmed in giant ragweed in Ontario [9]. Developing herbicide programs that contain a herbicide other than glyphosate and ALS inhibitors could limit further selection of herbicide resistant giant ragweed in agronomic fields.

Glyphosate-resistant (GR) giant ragweed can be controlled in soybean with glyphosate plus 2,4-D ester or amitrole applied preplant. [10] [11]. However, mixing glyphosate with other herbicides having residual activity provided variable and generally unacceptable control of GR giant ragweed [10]. While more reliable control was obtained with a post-emergence application of cloransulam methyl [11], the presence of multiple resistant giant ragweed populations makes this treatment ineffective in some fields [9]. This highlights the need to evaluate alternative herbicides for sustainable management of this weed.

New herbicide resistance traits in crops could provide new weed control strategies for the control of GR giant ragweed. Bayer CropScience is developing an IFT-resistant soybean that will have resistance to isoxaflutole (IFT), an inhibitor of 4-hydroxyphenylpyruvate dioxygenase (HPPD), and to glyphosate [12]. The IFT-resistant technology will allow isoxaflutole to be integrated into soybean weed management programs which will provide burndown and residual control of susceptible weed species [13]. Since isoxaflutole will be a major tool in IFT-resistant technology, it is important to test possible tank-mix partners to classify the interaction as additive, synergistic, or antagonistic.

Herbicide combinations or tank-mixes, can provide broader spectrum or longer control depending on the herbicides that are combined. The combination of herbicides can result in a response that is different from what would be expected from each product applied alone. For example synergism occurs when the observed level of control from a herbicide combination is greater than the expected level of control of the herbicides applied separately. Conversely, antagonism is when the observed control is less than what would be expected based on the herbicides applied separately. When the observed control is equal to what would be expected, the response is considered additive [14]. Since it is possible that glyphosate will be applied alongside IFT in IFT-resistant soybean, it is important to determine the interaction.

HPPD-inhibitors, when applied in combination with photosystem II inhibitors such as atrazine or metribuzin (MTZ) exhibit synergistic action on weeds [15] [16]. Since MTZ is a registered herbicide in soybean, there is an opportunity to add it to IFT, or to an IFT glyphosate mixture, in order to obtain a synergistic response. This would be desirable for the control of giant ragweed, especially when there are populations resistant to glyphosate.

The objectives of this study were to determine the doses of IFT plus MTZ required for obtaining acceptable control of GR giant ragweed under field conditions. In addition, the interactions between glyphosate and IFT, 
IFT and MTZ and the IFT + MTZ mixture and glyphosate were measured under greenhouse and growth room conditions.

\section{Materials and Methods}

\subsection{Field Trials}

Five field trials were conducted over a two-year period $(2013,2014)$ in southwestern Ontario with previously confirmed GR giant ragweed. Location, soil characteristics, spray date, and giant ragweed height and density at application for each site is listed in Table 1. Experiments were arranged in a randomized complete block design with four replicates. Plots were $2 \mathrm{~m}$ wide by $8 \mathrm{~m}$ long. Herbicide treatments were applied between May $9^{\text {th }}$ and May $20^{\text {th }}$ in 2013 and 2014 targeting giant ragweed plants at the four-leaf stage or up to $10 \mathrm{~cm}$ in height. The herbicides were applied with a $\mathrm{CO}_{2}$ pressurized backpack sprayer calibrated to apply $200 \mathrm{~L} \cdot \mathrm{ha}^{-1}$ at $240 \mathrm{kPa}$. The spray boom was $1.5 \mathrm{~m}$ wide with four ultra-low drift nozzles (ULD120-02, Hypro, New Brighton, MN) spaced $50 \mathrm{~cm}$ apart. Weedy and weed free controls were included in each replicate of each experiment. The weedy control was sprayed with glyphosate $\left(900 \mathrm{~g}\right.$ a.e. $\left.\mathrm{ha}^{-1}\right)$ to remove all other weed species with the exception of the GR giant ragweed. The weed-free control was sprayed with glyphosate $\left(900 \mathrm{~g}\right.$ a.e. $\mathrm{ha}^{-1}$ ) and 2,4-D ester (500 g a.e. $\mathrm{ha}^{-1}$ ). Weed-free controls were maintained using subsequent hand hoeing as needed.

All treatments included glyphosate at $900 \mathrm{~g}$ a.e. $\mathrm{ha}^{-1}$. Treatments included three rates of IFT (52, 79, and 105 g a.i. $\left.\mathrm{ha}^{-1}\right)$, three rates of MTZ $\left(210,316\right.$, and $420 \mathrm{~g}$ a.i. ha $\left.{ }^{-1}\right)$ and six rates of IFT plus MTZ applied in combination $\left(26.25+105,52.5+210,79+316,105+420,210+840\right.$ and $\left.420+1680 \mathrm{~g}_{\text {a.i. }} \mathrm{ha}^{-1}\right)$. The IFT plus MTZ treatments represent a 1:4 ratio of the active ingredients (1 part IFT to 4 parts MTZ). Linuron, amitrole and 2,4-D at 2250, 2000 and 500 g a.i./a.e. ha ${ }^{-1}$, respectively were included as industry standards for comparison purposes.

GR giant ragweed control was visually estimated at 4 and 8 week after application (WAA) on a scale of $0 \%$ (no control) to $100 \%$ (complete plant death). GR giant ragweed plant counts were conducted at application, 4 and 8 WAA. GR giant ragweed plants were counted in two $0.25 \mathrm{~m}^{2}$ quadrats in the untreated control at each rating event. At 8 WAA, GR giant ragweed in two $0.25 \mathrm{~m}^{2}$ quadrats were counted, cut at the soil surface, and dried at $60^{\circ} \mathrm{C}$ for 72 hours. The GR giant ragweed density and dry weights were recorded.

No crop was seeded in any field experiments due to unavailability of IFT-resistant soybean. This study was designed to focus on weed control, thus, herbicide application targeted the weed stage, when giant ragweed plants were at the 4-leaf stage or up to $10 \mathrm{~cm}$ in height.

\subsection{Growth Room Experiments}

One experiment was conducted on GR and GS giant ragweed biotypes in a growth room at the University of Guelph to determine the response of giant ragweed to glyphosate and IFT in combination. Two phenotypic

Table 1. Location, soil characteristics, spray date, and giant ragweed height and density at application for field studies in Ontario, Canada in 2013 and 2014 .

\begin{tabular}{|c|c|c|c|c|c|c|c|c|c|c|c|c|}
\hline \multirow{3}{*}{ Site } & \multirow{3}{*}{ Location } & \multirow{3}{*}{ Year } & \multicolumn{4}{|c|}{ Soil Characteristics } & \multirow{2}{*}{$\mathrm{OM}$} & \multirow{2}{*}{$\mathrm{pH}$} & \multirow{2}{*}{ CEC } & \multirow{3}{*}{$\begin{array}{l}\text { Spray } \\
\text { Date }\end{array}$} & \multicolumn{2}{|c|}{ Giant Ragweed } \\
\hline & & & Sand & Slit & Clay & Classification & & & & & Height & Density \\
\hline & & & \multicolumn{4}{|c|}{ 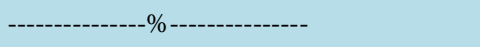 } & $\%$ & $\mathrm{CaCl}_{2}$ & $\mathrm{Cmol}_{\mathrm{C}} \mathrm{kg}^{-1}$ & & $\mathrm{~cm}$ & No. $\mathrm{m}^{-2}$ \\
\hline $\mathrm{S} 1$ & Harrow & 2013 & 27.2 & 33.6 & 39.2 & clay loam & 3.7 & 7.3 & 17.9 & 17-May & 8 & 267 \\
\hline $\mathrm{S} 2$ & Harrow & 2013 & 55.2 & 26.6 & 18.2 & sandy loam & 4 & 7.7 & 16.9 & 09-May & 9 & 214 \\
\hline S3 & Tilbury & 2013 & 21.1 & 36.6 & 42.2 & clay & 3.1 & 7.9 & 21.9 & 09-May & 8 & 181 \\
\hline S4 & Harrow & 2014 & 51 & 28.4 & 20.6 & loam & 3.2 & 7.4 & 15.5 & 16-May & 10 & 48 \\
\hline S5 & Harrow & 2014 & 22 & 38.9 & 39.1 & clay loam & 4.1 & 7.4 & 20.5 & 20-May & 8 & 330 \\
\hline
\end{tabular}

a Abbreviations: CEC, cation exchange capacity; OM, organic matter. 
responses have been observed in GR giant ragweed, with the two distinct biotypes referred to as "rapid necrosis" and "slow recovery". Leaves from rapid necrosis plants will rapidly curl after exposure to glyphosate and become necrotic within 24 hours after application, while the apical growing point remains unaffected; in contrast slow recovery plants appear to halt their growth for several days following glyphosate application, showing low level chlorosis of the leaf margins, growth resumes after several days. In Ontario, the rapid necrosis phenotype is more common than the slow recovery [11], but due to seed availability the slow recovery GR biotype was tested. To induce germination, giant ragweed seeds were wrapped in a fine nylon mesh to make a 3 to $5 \mathrm{~cm}$ diameter bundle, placed in moist sand and placed in a refrigerator set at $4^{\circ} \mathrm{C}$ for 4 to 8 weeks. After the cold stratification period, the seeds were placed $1 \mathrm{~cm}$ deep in plastic germination trays $(50 \times 25 \times 5 \mathrm{~cm})$ filled with potting mix (PRO-MIX PGX, Premier Tech Horticulture, Rivière-du-Loup, QC, Canada). Upon cotyledon emergence, single plants were transplanted into a $10 \mathrm{~cm}$ diameter pot containing the same potting mix. Seedlings were watered and placed in a growth room under a 16 hour photophase at $25^{\circ} \mathrm{C}$ and an 8 hour scotophase at $20^{\circ} \mathrm{C}$. Plants were watered and fertilized as required using a solution of $2.0 \mathrm{~g} \cdot \mathrm{L}^{-1}$ of 20:20:20 (N:P:K).

Thirty-six treatments were applied combining six rates of glyphosate and six rates of IFT. Glyphosate rates used for the GS biotype were $0,28.25,56.25,112.5,225$, and $450 \mathrm{~g}$ a.e. $\mathrm{ha}^{-1}$ and for the GR biotype were 0,225 , 450, 900, 1800, and $3600 \mathrm{~g}$ a.e. ha ${ }^{-1}$. The rates of IFT evaluated were $0,6.5,13,26.25,52.5$, and $105 \mathrm{~g}$ a.i. ha ${ }^{-1}$ for both the GR and GS biotypes. Treatments in each experiment were arranged as a 6 by 6 factorial in a randomized complete block design with four replications and conducted twice. Prior to herbicide application, plants were selected so that they were as uniform as possible targeting $10 \mathrm{~cm}$ in height or the four-leaf stage. Herbicides were applied using a single nozzle track sprayer equipped with a TeeJet TP8002E-SS nozzle tip (Spraying Systems Co., Glendale Heights, IL USA) calibrated to deliver $210 \mathrm{~L} \cdot \mathrm{ha}^{-1}$ at $275 \mathrm{kPa}$. Plants were returned to the growth chamber after treatment and grown under the same conditions as above. Giant ragweed plants were cut at the soil surface at $5 \mathrm{WAA}$, dried at $60^{\circ} \mathrm{C}$ for 72 hours and the dry weight was then recorded.

\subsection{Greenhouse Experiments}

Two experiments were conducted in a greenhouse at the University of Guelph Ridgetown Campus. The experiments were conducted on a previously confirmed GR population of giant ragweed. The experiments were conducted as a two factor factorial experiment with four replicates and each experiment was repeated twice.

Plants were grown as above but with a different potting mix (Sunshine Mix LA4, Sun Gro Horticulture Canada, Seba Beach, Alberta, Canada). Seedlings were watered and placed in a greenhouse under a 16 hour photophase at $25^{\circ} \mathrm{C}$ and an 8 hour scotophase at $18^{\circ} \mathrm{C}$. All plants were watered daily. Treatments were applied when plants were $10 \mathrm{~cm}$ in height or the four-leaf stage.

Experiment 1 compared seven rates of IFT $\left(0,26.25,52.5,79,105,210\right.$ and $420 \mathrm{~g}$ a.i. ha $\left.{ }^{-1}\right)$ and seven rates of $\operatorname{MTZ}\left(0,105,210,316,420,840\right.$ and $1680 \mathrm{~g}$ a.i. ha $\left.{ }^{-1}\right)$. All treatments included glyphosate at $450 \mathrm{~g}$ a.e. ha ${ }^{-1}$.

Experiment 2 included seven rates of IFT plus MTZ (0, $26.25+105,52.5+210,79+316,105+420,210+$ 840 and $420+1680 \mathrm{~g}$ a.i. $\left.\mathrm{ha}^{-1}\right)$ in a tank-mix and seven rates of glyphosate $(0,225,450,675,900,1800,3600$ g a.e. ha ${ }^{-1}$ ). Control ratings were completed at 1, 2, 3, 4 and 5 WAA and giant ragweed biomass was determined at 5 WAA by cutting the plants at the soil surface, drying them at $60^{\circ} \mathrm{C}$ and recording the dry weight.

\subsection{Statistical Analysis}

\subsubsection{Field Experiments}

PROC NLIN in SAS (Ver. 9.2, SAS Institute Inc., Cary NC) was used to regress giant ragweed control, density and dry weight with the biologically effective rate of the IFT plus MTZ. The exponential to maximum function was used for the analysis of the control ratings in the form:

$$
\mathrm{Y}=\mathrm{a}+\mathrm{b}\left(1-\mathrm{e}^{-\mathrm{cx}}\right)
$$

The inverse of the exponential to maximum was used for the density and dry weight analysis in the form:

$$
\mathrm{Y}=\mathrm{a}+\mathrm{be}^{-\mathrm{cx}}
$$

where "a" is the lower asymptote or origin value, "b" is the change in "Y" from the intercept and "c" is the slope at the point of inflection. Effective dose (ED) was calculated using the equation of the curve.

PROC MIXED was used to compare the commercial treatments to the current high label rate of IFT plus 
MTZ tank-mix $\left(105+420\right.$ g a.i. ha $\left.^{-1}\right)$. Variances were separated into fixed effects of herbicide treatment and environment and random effects of replication and location (location and year) by treatment interaction. The significance of the random effects was tested using the $\mathrm{Z}$ test. The interaction between the fixed and random effects was also tested using the $\mathrm{Z}$ test. The $\mathrm{F}$ test was used to test the significance of the fixed effects. If the location by treatment interaction was non-significant then sites were combined for analysis. Error terms were checked for independence and homogeneity using residual plots. The UNIVARIATE procedure was used to generate the Shapiro-Wilk statistic to test for normality. When transforming the data (natural log, square root, or arcsine square root), the highest Shapiro-Wilk statistic was used when necessary. All sites could be combined for analysis using untransformed data for control 4 WAA while the log transformation was used for control 8 WAA, density, and biomass and all sites were combined for analysis. Means presented are back transformed values when a transformation was used. Fisher's protected LSD at $\mathrm{P}<0.05$ was used to separate means.

\subsubsection{Growth Room and Greenhouse Experiments}

The statistical method used to analyze the growth room and greenhouse experiments is that developed by Flint $e t$ al. [17] which is an adaptation of Colby's method [14] for analyzing antagonistic, additive and synergistic response of herbicide mixtures.

Data was transformed to logarithms and then estimates and significance tests of all 2 by 2 interaction contrasts in the form of:

$$
\mathrm{I}_{\mathrm{ij}}=\mathrm{u}_{\mathrm{ij}}-\mathrm{u}_{\mathrm{i} 0}-\mathrm{u}_{0 \mathrm{j}}+\mathrm{u}_{00},
$$

where "i" and " $\mathrm{j}$ " are non-zero rates of herbicides A and B, respectively and " $\mathrm{u}$ " represents the parametric mean of the transformed values. The zero subscript represents the zero dose of the herbicide. If $\mathrm{I}_{\mathrm{ij}}<0$, synergism is implied whereas if $I_{i j}>0$ antagonism is implied. Therefore, the statistical estimates given by the analysis are considered antagonistic if significantly positive, or synergistic if significantly negative. A non-significant value is considered an additive response [17]. This method was also used for the analysis of the three tank-mix rates used in the field experiments.

\section{Results and Discussion}

\subsection{Biologically Effective Dose of Isoxaflutole and Metribuzin Combination}

Glyphosate (900 g a.e. ha ${ }^{-1}$ ) was applied in all treatments at every site in order to control all weeds except GR giant ragweed.

Increasing the dose of the IFT plus MTZ mixtures (1:4 ratio) resulted in increased level of GR giant ragweed control (Table 2). At 4 WAA, the estimated dose of IFT plus MTZ for $50 \%, 80 \%$, and $95 \%$ control of giant ragweed (LD values) were 223, 518, and $963 \mathrm{~g}$ a.i. $\mathrm{ha}^{-1}$, respectively. The level of control was slightly reduced at 8 WAA with LD values increasing by $22 \%$ (Table 2). In Canada, $105 \mathrm{~g}$ a.i. $\mathrm{ha}^{-1}$ is the maximum rate of IFT that is currently registered, plus the addition of MTZ at $420 \mathrm{~g}$ a.i. $\mathrm{ha}^{-1}$ corresponds to the $525 \mathrm{~g}$ a.i. $\mathrm{ha}^{-1}$ treat- $^{-}$ ment. This approximates the value of the $\mathrm{LD}_{80}$ observed for this mixture. This means that under the conditions where these experiments were conducted, the IFT plus MTZ mixture did not provide 95\% control.

At 8 WAA, 288, 668 and 1243 g a.i. ha ${ }^{-1}$ of IFT plus MTZ was required for a 50, 80 and 95\% reduction in giant ragweed density, respectively (Table 2), while reduction of biomass by the same levels was achieved by doses of 201, 467, and $867 \mathrm{~g}$ a.i. $\mathrm{ha}^{-1}$, respectively (Table 2). Of all the variables evaluated in this study, the effective doses were lowest for GR giant ragweed biomass. While visible control and weed density are relatively easy variables to evaluate, weed biomass is a better predictor of the competitive ability of a weed [18]. Therefore, the fact that biomass was most impacted by the herbicides suggests that the effect of the weeds on a crop would be less than what could be visually estimated. As these experiments were conducted in the absence of a crop it is therefore likely that in the presence of a soybean crop, the impact of the herbicides on giant ragweed biomass would have been greater. While in this study, the maximum registered dose of a an IFT plus MTZ mixture (525 g a.i. ha ${ }^{-1}$ ) reduced giant ragweed biomass approximately $80 \%$ an application with a competing soybean crop would likely result a greater biomass reduction. The impact of IFT plus MTZ giant ragweed biomass is a more accurate measurement of weed interference than other parameters evaluated.

The interaction between IFT and MTZ for the control of GR giant ragweed is synergistic as indicated by estimates of Flint's adaptation (Table 3). Control ratings at 4 and 8 WAA across all five sites returned a significant 
Table 2. Dose response of isoxaflutole plus metribuzin tank-mix on the control of glyphosate-resistant giant ragweed, density and dry weight in five field studies conducted in 2013 and 2014.

\begin{tabular}{|c|c|c|c|c|c|c|c|}
\hline Dose response & $\begin{array}{l}\text { Time } \\
\text { WAA }^{\mathrm{e}}\end{array}$ & $b^{\mathrm{a}}$ & $\begin{array}{l}a^{b} \\
\%\end{array}$ & $c^{c}$ & $E D_{50}{ }^{d}$ & $\mathrm{ED}_{80}$ & $\mathrm{ED}_{95}$ \\
\hline \multicolumn{8}{|l|}{ Exponential to Maximum } \\
\hline Visible control (\%) & 4 & $101.6(3.3)$ & 0 & $0.0031(0.0003)$ & 222.8 & 517.5 & 963.3 \\
\hline Visible control (\%) & 8 & $103.8(3.8)$ & 0 & $0.0026(0.0002)$ & 271.8 & 631.2 & 1174.8 \\
\hline \multicolumn{8}{|c|}{ Inverse Exponential to Maximum } \\
\hline Density & 8 & $115.2(15)$ & 0 & $0.0024(0.0007)$ & 287.6 & 667.8 & 1243 \\
\hline Biomass & 8 & $105.2(6.9)$ & 0 & $0.0035(0.0004)$ & 200.9 & 466.5 & 867.2 \\
\hline
\end{tabular}

${ }^{a} \mathrm{~b}$ is the maximum; ${ }^{b} \mathrm{a}$ is the asymptote or the origin value; ${ }^{\mathrm{c}} \mathrm{C}$ is the slope or the rate at which half the effect is observed; ${ }^{\mathrm{d}} \mathrm{ED}=$ the effective dose for 50 , 80 , and $95 \%$ control or reduction in biomass or density rates correspond to isoxaflutole and metribuzin active ingredient only in a 1 to 4 ratio; WAA, weeks after application.

Table 3. Flint's analysis of isoxaflutole plus metribuzin tank-mix from field studies of control 4 and 8 WAA and dry weight at 8 WAA for 2013 and 2014 in Ontario, Canada ${ }^{a}$.

\begin{tabular}{|c|c|c|c|c|}
\hline \multirow{2}{*}{ Rating } & \multirow{2}{*}{$\begin{array}{c}\text { Rate } \\
\text { IFT + MTZ }\end{array}$} & \multicolumn{3}{|c|}{ Regression Statistics } \\
\hline & & Estimate & Standard error & $\operatorname{Pr}>|t|$ \\
\hline \multirow{4}{*}{$\begin{array}{l}\text { 4 WAA } \\
\text { S1-5 }\end{array}$} & $0+0$ & 0.039 & 0.099 & 0.6959 \\
\hline & $52.5+210$ & -0.531 & 0.199 & 0.0082 \\
\hline & $79+316$ & -0.600 & 0.199 & 0.0029 \\
\hline & $105+420$ & -0.843 & 0.199 & $<0.0001$ \\
\hline \multirow{4}{*}{$\begin{array}{l}8 \text { WAA } \\
\text { S1-5 }\end{array}$} & $0+0$ & 0 & 0.102 & 1 \\
\hline & $52.5+210$ & -0.531 & 0.203 & 0.0098 \\
\hline & $79+316$ & -0.643 & 0.203 & 0.0018 \\
\hline & $105+420$ & -0.810 & 0.203 & $<0.0001$ \\
\hline \multirow{4}{*}{$\begin{array}{l}\text { Dry Weight } \\
\text { S1-5 }\end{array}$} & $0+0$ & 2.00 & 0.092 & $<0.0001$ \\
\hline & $52.5+210$ & 0.003 & 0.184 & 0.9885 \\
\hline & $79+316$ & -0.635 & 0.184 & 0.0008 \\
\hline & $105+420$ & -0.492 & 0.184 & 0.0083 \\
\hline
\end{tabular}

abbreviations: WAA, weeks after application; IFT, isoxaflutole; MTZ, metribuzin; S Site.

negative estimate indicating synergism. While the same analysis of the weed biomass data returned a non-significant positive estimate at the low rate, the analysis gave significant negative estimates at the medium and high rates. The positive estimate is non-significant, therefore indicating an additive response while the medium and high rates would indicate synergism. These findings are similar to those of Woodyard et al. [16] where a tank-mix of the HPPD-inhibitor mesotrione plus atrazine showed synergism. The tank-mix of IFT plus MTZ is synergistic for the control of GR ragweed under field conditions.

A comparison of means between commercial standards and the $105+420 \mathrm{~g}$ a.i. ha $^{-1}$ rate of IFT plus MTZ (Table 4) showed similar efficacy at 8 WAA. In contrast, at 4 WAA, IFT plus MTZ provided $87 \%$ control of GR giant ragweed, which was less than the weed free control and amitrole (98\%) but equivalent to 2,4-D (92\%) 
Table 4. Glyphosate-resistant giant ragweed control at 4 and 8 WAA, and density and biomass at 8 WAA from studies conducted in 2013 and 2014 in Ontario, Canada ${ }^{\text {a,b }}$.

\begin{tabular}{|c|c|c|c|c|c|}
\hline \multirow{3}{*}{ Treatment } & \multirow{2}{*}{ Rate } & 4 WAA & 8 WAA & Density & $\%$ Biomass \\
\hline & & S1-5 & S1-5 & S1-5 & S1-5 \\
\hline & g a.i/a.e ha ${ }^{-1}$ & $\%$ & $\%$ & $\%$ of control & $\%$ of control \\
\hline Weedy Check & & - & - & $100^{\mathrm{a}}$ & $100^{\mathrm{a}}$ \\
\hline Weed Free & & $100^{\mathrm{a}}$ & $100^{\mathrm{a}}$ & - & - \\
\hline 2,4-D & 500 & $92^{\mathrm{b}} \mathrm{c}$ & $86^{\mathrm{b}}$ & $11^{\mathrm{b}}$ & $3^{\mathrm{b}}$ \\
\hline Amitrole & 2000 & $98^{\mathrm{ab}}$ & $93^{\mathrm{ab}}$ & $2^{b}$ & $2^{\mathrm{b}}$ \\
\hline Linuron & 2250 & $93^{\mathrm{b}} \mathrm{c}$ & $88^{\mathrm{b}}$ & $5^{\mathrm{b}}$ & $2^{\mathrm{b}}$ \\
\hline isoxaflutole + metribuzin & $105+420$ & $87 \mathrm{c}$ & $86^{\mathrm{b}}$ & $11^{\mathrm{b}}$ & $5^{\mathrm{b}}$ \\
\hline
\end{tabular}

${ }^{\mathrm{a}}$ Abbreviations: WAA, weeks after application; IFT, isoxaflutole; MTZ, metribuzin; S Site; ${ }^{\mathrm{b}}$ Means followed by the same letter within a column are not significantly different according to Fisher's Protected LSD at $\mathrm{P}<0.05$.

and linuron (93\%). At 8 WAA, IFT plus MTZ provided 86\% control of GR giant ragweed, which was equivalent to the treatments containing 2,4-D, amitrole or linuron. For both the density and biomass evaluations IFT plus MTZ was equivalent to the commercial standards and all treatments were less than the weedy control. The herbicide treatments evaluated in this study reduced GR giant ragweed density by $89 \%$ to $98 \%$ and biomass by $95 \%$ to $98 \%$.

Vink et al. [5] reported that 2,4-D ester and glyphosate plus 2,4-D ester provided control of GR giant ragweed that was equivalent to the weed-free control. Other studies observed variable control using 2,4-D [2] [19].

\subsection{Determination of the Glyphosate IFT Interaction}

The two factor factorial trials performed in the growth room assessed the response of glyphosate and IFT tank-mixes on GS and GR giant ragweed biotypes. Of the 25 tank-mix treatments of glyphosate plus IFT, when applied to GS giant ragweed, eight treatments (shown in bold in Table 5) returned a significantly positive estimate indicating an antagonistic response (Table 5). All other estimates are non-significant indicating an additive response. Although eight treatments indicate an antagonistic response in the GS giant ragweed, the glyphosate rates included in the experiment are less than the field rate of $900 \mathrm{~g}$ a.e. $\mathrm{ha}^{-1}$. The antagonism may decrease as the rate of glyphosate increases as observed in another study [20].

Analysis of the GR giant ragweed biotype indicates an additive response across all treatments. All treatment estimates are non-zero and non-significant indicating an additive response. The characteristic slow recovery of this biotype of giant ragweed to an application of glyphosate could allow IFT to be effective. It would be interesting to determine the effect of glyphosate and IFT on GR ragweed with the rapid necrosis phenotype as it may lead to different results.

\subsection{Determination of the Glyphosate Interaction with IFT plus MTZ}

Greenhouse experiments were performed to determine the control of GR giant ragweed in response to IFT plus MTZ in combination with glyphosate. All tank-mix treatment estimates of control of GR giant ragweed in response to IFT plus MTZ are significantly negative, indicating synergism (Table 6). Similarly, the experiment to determine the effect of increasing glyphosate rates versus increasing IFT plus MTZ mixed in a 1:4 ratio (Table 7), showed that all tank-mix treatments were synergistic at 2 WAA. Similar to results of the field experiments, the synergism of IFT plus MTZ tank-mixes corroborates with other studies involving tank-mixes of HPPD and PSII inhibiting herbicides [15] [16]. The synergism between IFT and MTZ is not negated by increasing glyphosate dose. In both experiments, nearly all tank-mix treatments resulted in complete death of the plant. Analysis of the dry weights using Flint's adaptation [17] returned expected values that are not biologically achievable. Since expected plant biomass cannot be a negative value, the statistical output resulted in false antagonism similar to high rate combinations used in other studies [15]. 
Table 5. Flint's analysis of glyphosate plus isoxaflutole tank-mixes on glyphosate susceptible and resistant giant ragweed dry weight at $5 \mathrm{WAA}^{\mathrm{a}, \mathrm{b}}$.

\begin{tabular}{|c|c|c|c|c|c|c|c|}
\hline \multicolumn{2}{|c|}{ Herbicide } & \multicolumn{3}{|c|}{ Glyphosate susceptible } & \multicolumn{3}{|c|}{ Glyphosate-resistant } \\
\hline IFT & GLY & Estimate & Standard Error & $\operatorname{Pr}>|t|$ & Estimate & Standard Error & $\operatorname{Pr}>|t|$ \\
\hline 0 & 0 & 0.793 & 1.221 & 0.5163 & 0.647 & 0.865 & 0.4546 \\
\hline 1 & 1 & 0.153 & 2.441 & 0.9499 & 0.364 & 1.730 & 0.8334 \\
\hline 1 & 2 & 1.736 & 2.441 & 0.4778 & 0.337 & 1.730 & 0.8455 \\
\hline 1 & 3 & 1.940 & 2.441 & 0.4276 & 1.225 & 1.730 & 0.4792 \\
\hline 1 & 4 & 1.927 & 2.441 & 0.4305 & -1.172 & 1.730 & 0.4985 \\
\hline 1 & 5 & -1.482 & 2.441 & 0.5444 & -1.846 & 1.730 & 0.2864 \\
\hline 2 & 1 & 2.833 & 2.441 & 0.247 & 0.421 & 1.730 & 0.8078 \\
\hline 2 & 2 & 2.905 & 2.441 & 0.2352 & -0.424 & 1.730 & 0.8066 \\
\hline 2 & 3 & 2.960 & 2.441 & 0.2265 & -1.671 & 1.730 & 0.3346 \\
\hline 2 & 4 & 3.362 & 2.441 & 0.1697 & -2.632 & 1.730 & 0.1288 \\
\hline 2 & 5 & -1.279 & 2.441 & 0.6009 & -1.701 & 1.730 & 0.3260 \\
\hline 3 & 1 & -2.309 & 2.441 & 0.3452 & 0.388 & 1.730 & 0.8224 \\
\hline 3 & 2 & 3.795 & 2.441 & 0.1214 & 0.777 & 1.730 & 0.6534 \\
\hline 3 & 3 & 5.373 & 2.441 & 0.0287 & -0.692 & 1.730 & 0.6892 \\
\hline 3 & 4 & 5.743 & 2.441 & 0.0194 & 0.005 & 1.730 & 0.9977 \\
\hline 3 & 5 & 0.040 & 2.441 & 0.9871 & -0.644 & 1.730 & 0.7097 \\
\hline 4 & 1 & 5.898 & 2.441 & 0.0164 & -0.345 & 1.730 & 0.8418 \\
\hline 4 & 2 & 7.302 & 2.441 & 0.0031 & 0.705 & 1.730 & 0.6836 \\
\hline 4 & 3 & 7.663 & 2.441 & 0.0019 & -1.493 & 1.730 & 0.3885 \\
\hline 4 & 4 & 10.289 & 2.441 & $<0.0001$ & -2.238 & 1.730 & 0.1965 \\
\hline 4 & 5 & 7.095 & 2.441 & 0.0040 & -0.627 & 1.730 & 0.7170 \\
\hline 5 & 1 & -1.186 & 2.441 & 0.6274 & 2.907 & 1.730 & 0.0936 \\
\hline 5 & 2 & 0.053 & 2.441 & 0.9826 & 3.146 & 1.730 & 0.0697 \\
\hline 5 & 3 & 2.745 & 2.441 & 0.2620 & 1.095 & 1.730 & 0.5271 \\
\hline 5 & 4 & 6.574 & 2.441 & 0.0076 & 1.114 & 1.730 & 0.5199 \\
\hline 5 & 5 & 2.403 & 2.441 & 0.3259 & 2.775 & 1.730 & 0.1095 \\
\hline
\end{tabular}

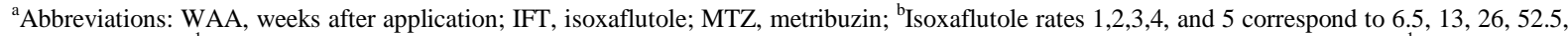
and $105 \mathrm{~g}$ a.i. ha ${ }^{-1}$ respectively; Glyphosate doses used for the susceptible biotype were $0,28.25,56.25,112.5,225$, and $450 \mathrm{~g}$ a.e. ha ${ }^{-1}$ and for the resistant biotype were $0,225,450,900,1800$, and 3600 g a.e. ha ${ }^{-1}$. 
Table 6. Flint's analysis of two factor factorial experiment of isoxaflutole versus metribuzin control of glyphosate-resistant giant ragweed 2 WAA from greenhouse studies conducted in Ontario, Canada in 2013 and 2014,

\begin{tabular}{|c|c|c|c|c|}
\hline \multicolumn{2}{|c|}{ Herbicide } & \multirow{2}{*}{ Estimate } & \multirow{2}{*}{ Standard error } & \multirow{2}{*}{$\operatorname{Pr}>|t|$} \\
\hline IFT & MTZ & & & \\
\hline 0 & 0 & 0 & 0.019 & 1 \\
\hline 1 & 1 & -0.628 & 0.038 & $<0.0001$ \\
\hline 1 & 2 & -0.874 & 0.038 & $<0.0001$ \\
\hline 1 & 3 & -0.778 & 0.038 & $<0.0001$ \\
\hline 1 & 4 & -0.876 & 0.038 & $<0.0001$ \\
\hline 1 & 5 & -0.900 & 0.038 & $<0.0001$ \\
\hline 1 & 6 & -0.905 & 0.038 & $<0.0001$ \\
\hline 2 & 1 & -0.621 & 0.038 & $<0.0001$ \\
\hline 2 & 2 & -0.877 & 0.038 & $<0.0001$ \\
\hline 2 & 3 & -0.793 & 0.038 & $<0.0001$ \\
\hline 2 & 4 & -0.891 & 0.038 & $<0.0001$ \\
\hline 2 & 5 & -0.915 & 0.038 & $<0.0001$ \\
\hline 2 & 6 & -0.920 & 0.038 & $<0.0001$ \\
\hline 3 & 1 & -0.670 & 0.038 & $<0.0001$ \\
\hline 3 & 2 & -0.931 & 0.038 & $<0.0001$ \\
\hline 3 & 3 & -0.863 & 0.038 & $<0.0001$ \\
\hline 3 & 4 & -0.956 & 0.038 & $<0.0001$ \\
\hline 3 & 5 & -0.980 & 0.038 & $<0.0001$ \\
\hline 3 & 6 & -0.985 & 0.038 & $<0.0001$ \\
\hline 4 & 1 & -0.647 & 0.038 & $<0.0001$ \\
\hline 4 & 2 & -0.934 & 0.038 & $<0.0001$ \\
\hline 4 & 3 & -0.846 & 0.038 & $<0.0001$ \\
\hline 4 & 4 & -0.943 & 0.038 & $<0.0001$ \\
\hline 4 & 5 & -0.968 & 0.038 & $<0.0001$ \\
\hline 4 & 6 & -0.973 & 0.038 & $<0.0001$ \\
\hline 5 & 1 & -0.672 & 0.038 & $<0.0001$ \\
\hline 5 & 2 & -0.948 & 0.038 & $<0.0001$ \\
\hline 5 & 3 & -0.860 & 0.038 & $<0.0001$ \\
\hline 5 & 4 & -0.957 & 0.038 & $<0.0001$ \\
\hline 5 & 5 & -0.982 & 0.038 & $<0.0001$ \\
\hline 5 & 6 & -0.987 & 0.038 & $<0.0001$ \\
\hline 6 & 1 & -0.667 & 0.038 & $<0.0001$ \\
\hline 6 & 2 & -0.966 & 0.038 & $<0.0001$ \\
\hline 6 & 3 & -0.871 & 0.038 & $<0.0001$ \\
\hline 6 & 4 & -0.969 & 0.038 & $<0.0001$ \\
\hline 6 & 5 & -0.993 & 0.038 & $<0.0001$ \\
\hline 6 & 6 & -0.998 & 0.038 & $<0.0001$ \\
\hline
\end{tabular}

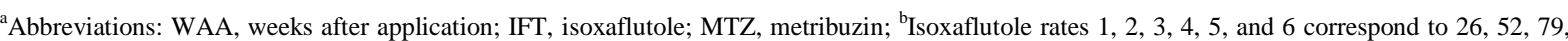
105, 210, and $420 \mathrm{~g}$ a.i. ha ${ }^{-1}$ respectively. Metribuzin rates $1,2,3,4,5$, and 6 correspond to 105, 210, 316, 420, 840, and $1680 \mathrm{~g}^{2}$.i. ha ${ }^{-1}$, respectively. 
Table 7. Flint's analysis of two factor factorial experiment of isoxaflutole plus metribuzin versus glyphosate control of glyphosate-resistant giant ragweed at 2 WAA from greenhouse studies conducted in Ontario, Canada in 2013 and $2014^{\mathrm{a}, \mathrm{b}}$.

\begin{tabular}{|c|c|c|c|c|}
\hline \multicolumn{2}{|c|}{ Herbicide } & \multirow{2}{*}{ Estimate } & \multirow{2}{*}{ Standard error } & \multirow{2}{*}{$\operatorname{Pr}>|t|$} \\
\hline $\mathrm{IFT}+\mathrm{MTZ}$ & GLY & & & \\
\hline 0 & 0 & 0.000 & 0.016 & 1 \\
\hline 1 & 1 & -0.378 & 0.033 & $<0.0001$ \\
\hline 1 & 2 & -0.601 & 0.033 & $<0.0001$ \\
\hline 1 & 3 & -0.678 & 0.033 & $<0.0001$ \\
\hline 1 & 4 & -0.714 & 0.033 & $<0.0001$ \\
\hline 1 & 5 & -0.900 & 0.033 & $<0.0001$ \\
\hline 1 & 6 & -0.968 & 0.033 & $<0.0001$ \\
\hline 2 & 1 & -0.389 & 0.033 & $<0.0001$ \\
\hline 2 & 2 & -0.601 & 0.033 & $<0.0001$ \\
\hline 2 & 3 & -0.695 & 0.033 & $<0.0001$ \\
\hline 2 & 4 & -0.730 & 0.033 & $<0.0001$ \\
\hline 2 & 5 & -0.900 & 0.033 & $<0.0001$ \\
\hline 2 & 6 & -0.979 & 0.033 & $<0.0001$ \\
\hline 3 & 1 & -0.389 & 0.033 & $<0.0001$ \\
\hline 3 & 2 & -0.601 & 0.033 & $<0.0001$ \\
\hline 3 & 3 & -0.695 & 0.033 & $<0.0001$ \\
\hline 3 & 4 & -0.730 & 0.033 & $<0.0001$ \\
\hline 3 & 5 & -0.905 & 0.033 & $<0.0001$ \\
\hline 3 & 6 & -0.979 & 0.033 & $<0.0001$ \\
\hline 4 & 1 & -0.394 & 0.033 & $<0.0001$ \\
\hline 4 & 2 & -0.601 & 0.033 & $<0.0001$ \\
\hline 4 & 3 & -0.695 & 0.033 & $<0.0001$ \\
\hline 4 & 4 & -0.730 & 0.033 & $<0.0001$ \\
\hline 4 & 5 & -0.900 & 0.033 & $<0.0001$ \\
\hline 4 & 6 & -0.973 & 0.033 & $<0.0001$ \\
\hline 5 & 1 & -0.389 & 0.033 & $<0.0001$ \\
\hline 5 & 2 & -0.601 & 0.033 & $<0.0001$ \\
\hline 5 & 3 & -0.695 & 0.033 & $<0.0001$ \\
\hline 5 & 4 & -0.735 & 0.033 & $<0.0001$ \\
\hline 5 & 5 & -0.900 & 0.033 & $<0.0001$ \\
\hline 5 & 6 & -0.994 & 0.033 & $<0.0001$ \\
\hline 6 & 1 & -0.389 & 0.033 & $<0.0001$ \\
\hline 6 & 2 & -0.601 & 0.033 & $<0.0001$ \\
\hline 6 & 3 & -0.695 & 0.033 & $<0.0001$ \\
\hline 6 & 4 & -0.730 & 0.033 & $<0.0001$ \\
\hline 6 & 5 & -0.900 & 0.033 & $<0.0001$ \\
\hline 6 & 6 & -0.979 & 0.033 & $<0.0001$ \\
\hline
\end{tabular}

${ }^{a}$ Abbreviations: WAA, weeks after application; IFT, isoxaflutole; MTZ, metribuzin; ${ }^{\mathrm{b}}$ Isoxaflutole plus metribuzin rates 1, 2, 3, 4, 5, and 6 correspond to $26,52,79,105,210$, and $420 \mathrm{~g}$ a.i. ha ${ }^{-1}$ respectively of isoxaflutole plus the appropriate 4 parts metribuzin. Glyphosate rates $1,2,3,4,5$, and 6 correspond to $225,450,675,900,1800$, and 3600 g a.e. ha ${ }^{-1}$, respectively. 


\section{Conclusion}

This study concludes that the interaction between isoxaflutole and metribuzin is synergistic for the control of GR giant ragweed. The interaction of isoxaflutole and glyphosate is additive for the biotype tested. Other biotypes of giant ragweed should be evaluated for their response to an isoxaflutole plus glyphosate tank-mix. The use of isoxaflutole plus metribuzin in IFT-resistant soybean will be a valuable option for soybean producers if used in a diverse crop rotation with multiple herbicide modes of action used over time. This will ensure the long-term use of the IFT-tolerant soybean system and reduce the selection pressure for herbicide resistant weed biotypes.

\section{References}

[1] Bassett, I.J. and Crompton, C.W. (1982) The Biology of Canadian Weeds. 55. Ambrosia trifida L. Canadian Journal of Plant Science, 62, 1003-1010. http://dx.doi.org/10.4141/cjps82-148

[2] Johnson, B., Loux, M., Nordby, D., Sprague, C., Nice, G., Westhoven, A. and Stachler, J. (2007) The Glyphosate, Weeds, and Crops Series: Biology and Management of Giant Ragweed (GWC-12). University of Purdue Extension, West Lafayette, 14 p.

[3] Baysinger, J.A. and Sims, B.D. (1991) Giant Ragweed (Ambrosia trifida) Interference in Soybean (Glycine max). Weed Science, 39, 358-362.

[4] Abul-Fatih, H.A. and Bazzaz, F.A. (1979) The Biology of Ambrosia trifida (L.) II. Germination, Emergence, Growth and Survival. New Phytologist, 83, 817-827. http://dx.doi.org/10.1111/j.1469-8137.1979.tb02313.x

[5] Vink, J.P., Soltani, N., Robinson, D.E., Tardif, F.J., Lawton, M.B. and Sikkema, P.H. (2012) Glyphosate-Resistant Giant Ragweed (Ambrosia trifida L.) Control with Preplant Herbicides in Soybean (Glycine max (L.) Merr.). Canadian Journal of Plant Science, 92, 913-922. http://dx.doi.org/10.4141/cjps2012-025

[6] Vink, J.P., Soltani, N., Robinson, D.E., Tardif, F.J., Lawton, M.B. and Sikkema, P.H. (2012) Occurrence and Distribution of Glyphosate-Resistant Giant Ragweed (Ambrosia trifida L.) in Southwestern Ontario. Canadian Journal of Plant Science, 92, 533-539. http://dx.doi.org/10.4141/cjps2011-249

[7] Heap, I. (2015) The International Survey of Herbicide Resistant Weeds. www.weedscience.org

[8] Soltani, N., Shropshire, C. and Sikkema, P.H. (2011) Giant Ragweed (Ambrosia trifida L.) Control in Corn. Canadian Journal of Plant Science, 91, 577-581. http://dx.doi.org/10.4141/cjps2010-004

[9] Follings, J., Soltani, N., Robinson, D.E., Tardif, F.J., Lawton, M.B. and Sikkema, P.H. (2013) Distribution of Glyphosate and Cloransulam-Methyl Resistant Giant Ragweed (Ambrosia trifida L.) Populations in Southern Ontario. Agricultural Science, 10, 570-576.

[10] Follings, J., Soltani, N., Robinson, D.E., Tardif, F.J., Lawton, M.B. and Sikkema, P.H. (2013) Control of Glyphosate Resistant Giant Ragweed in Soybean with Preplant Herbicides. Agricultural Science, 4, 195-205. http://dx.doi.org/10.4236/as.2013.44028

[11] Vink, J.P., Soltani, N., Robinson, D.E., Tardif, F.J., Lawton, M.B. and Sikkema, P.H. (2012) Glyphosate-Resistant Giant Ragweed (Ambrosia trifida L.) in Ontario: Dose Response and Control with Post Emergence Herbicides. American Journal of Plant Sciences, 3, 608-617. http://dx.doi.org/10.4236/ajps.2012.35074

[12] Young, B. (2009) Recent and Future Soybean Traits That Impact Weed Management. Indiana Certified Crop Advisor Conference Proceedings, Southern Illinois University. http://www.agry.purdue.edu/cca/2009/index.htm

[13] Matringe, M., Sailland, A., Pelissier, B., Rolland, A. and Zink, O. (2005) p-Hydroxyphenylpyruvate Dioxygenase Inhibitor-Resistant Plants. Pest Management Science, 61, 269-276. http://dx.doi.org/10.1002/ps.997

[14] Colby, S.R. (1967) Calculating Synergistic and Antagonistic Responses of Herbicide Combinations. Weeds, 15, 20-22. http://dx.doi.org/10.2307/4041058

[15] Hugie, J.A., Bollero, G.A., Tranel, P.J. and Riechers, D.E. (2008) Defining the Rate Requirements for Synergism between Mesotrione and Atrazine in Redroot Pigweed (Amaranthus retroflexus). Weed Science, 56, 265-270. http://dx.doi.org/10.1614/WS-07-128.1

[16] Woodyard, A.J., Bollero, G.A. and Riechers, D.E. (2009) Broadleaf Weed Management in Corn Utilizing Synergistic Postemergence Herbicide Combinations. Weed Technology, 23, 513-518. http://dx.doi.org/10.1614/WT-08-188.1

[17] Flint, J.L., Cornelius, P.L. and Barrett, M. (1988) Analyzing Herbicide Interactions: A Statistical Treatment of Colby’s Method. Weed Technology, 2, 304-309.

[18] Zimdahl, R.L. (2004) Weed-Crop Competition: A Review. Blackwell Publishing, Ames, 220 p. http://dx.doi.org/10.1002/9780470290224 
[19] Loux, M., Stachler, J., Johnson, B. and Nice, G. (2006) Management of Giant Ragweed in Roundup Ready Soybean Fields with a History of Poor Control. http://www.btny.purdue.edu/weedscience/2006/GiantRagweed06.pdf

[20] Selleck, G.W. and Baird, D.D. (1981) Antagonism with Glyphosate and Residual Herbicide Combinations. Weed Science, 29, 185-190. 